\title{
A Score to Identify Patients with Brain Metastases from Colorectal Cancer Who May Benefit from Whole-brain Radiotherapy in Addition to Stereotactic Radiosurgery/Radiotherapy
}

\author{
DIRK RADES ${ }^{1}$, LIESA DZIGGEL $^{1}$, OLIVER BLANCK ${ }^{2}$, NIKLAS GEBAUER $^{3}$, \\ TOBIAS BARTSCHT ${ }^{3}$ and STEVEN E. SCHILD ${ }^{4}$ \\ Departments of ${ }^{1}$ Radiation Oncology and ${ }^{3}$ Hematology and Medical Oncology, \\ University of Lübeck, Lübeck, Germany; \\ ${ }^{2}$ Saphir Radiosurgery Center Northern Germany, Güstrow, Germany; \\ ${ }^{4}$ Department of Radiation Oncology, Mayo Clinic, Scottsdale, AZ, U.S.A.
}

\begin{abstract}
Aim: To design a tool to predict the probability of new cerebral lesions after stereotactic radiosurgery/radiotherapy for patients with 1-3 brain metastases from colorectal cancer. Patients and Methods: In 21 patients, nine factors were evaluated for freedom from new brain metastases, namely age, gender, Karnofsky performance score (KPS), tumor type, number, maximum total diameter of all lesions and sites of cerebral lesions, extra-cranial metastases, and time from cancer diagnosis to irradiation. Results: Freedom from new lesions was positively associated with KPS of 90-100 ( $p=0.013)$; maximum total diameter $\leq 15 \mathrm{~mm}$ showed a trend for positive association ( $p=0.09)$. Points were assigned as: KPS 70-80=1 point, KPS 90-100=2 points, maximum diameter $\leq 15 \mathrm{~mm}=2$ points and maximum diameter $>15 \mathrm{~mm}=1$ point. Six-month rates of freedom from new lesions were 29\%, 45\% and $100 \%$ for those with total scores of 2, 3 and 4 points, respectively, with corresponding 12-month rates of 0\%, $45 \%$ and $100 \%$ ( $p=0.027)$. Conclusion: This study identified three risk groups regarding new brain metastases after stereotactic irradiation. Patients with 2 points could benefit from additional whole-brain radiotherapy.
\end{abstract}

Correspondence to: Professor Dirk Rades, MD, Department of Radiation Oncology, University of Lübeck, Lübeck, Ratzeburger Allee 160, 23562 Lübeck, Germany. Tel: +49 45150045401, Fax: +49 45150045404, e-mail: rades.dirk@gmx.net

Key Words: Colorectal cancer, brain metastases, stereotactic radiosurgery, fractionated stereotactic radiotherapy, new brain metastases, whole-brain radiotherapy, prognostic score.
Patients with colorectal cancer represent about $5 \%$ of patients referred to a radiation oncologist for treatment of brain metastases from solid cancers $(1,2)$. More than $50 \%$ of these patients have only 1-3 lesions and are often assigned to receive a local therapy such as resection, stereotactic radiosurgery (SRS) or fractionated stereotactic radiotherapy (FSRT) (1-3). A resection should only be performed in the case of a single brain metastasis which is well accessible and not involving critical structures such as the brain stem and speech center (2-4). For other patients, SRS and FSRT are better choices, either alone or combined with sequential whole-brain irradiation (WBI) (3). It is controversial which if any patients benefit from the addition of WBI to SRS or FSRT (5-7). The addition of WBI was associated with a more pronounced decline in neurocognitive function than SRS or FSRT alone $(5,6)$. However, WBI improved intracerebral control, mainly by preventing the development of new brain metastases outside the areas treated with SRS/FSRT, i.e. distant brain metastases. It was reported that the development of new cerebral lesions also results in a decline in neurocognitive function (7). Therefore, it would be important for treating radiation oncologists to be able to predict the probability of new distant brain metastases after SRS/FSRT alone before selecting the treatment regimen for an individual patient. To improve this decision-making process, the present study was performed to design a scoring tool to estimate the risk of new brain metastases after SRS or FSRT in patients with 1-3 brain metastases from colorectal cancer.

\section{Patients and Methods}

Twenty-one patients treated with SRS (15-20 Gy, median $18 \mathrm{~Gy}$ ) or FSRT (3-5 fractions of 8-11 Gy) alone for 1-3 brain metastases from 
colorectal cancer between 1999 and 2015 were included in this retrospective study. Nine factors were evaluated for associations with freedom from new cerebral metastases outside the irradiated regions of the brain, namely age at the time of SRS/FSRT ( $\leq 65 v s$. $\geq 66$ years, median $=66$ ), gender, Karnofsky performance score (KPS) (70-80 vs. 90-100, median=90), primary tumor type (colon cancer $v s$. rectal cancer), number of cerebral metastases (1 vs. 2-3), maximum total diameter of all cerebral lesions $(\leq 15 \mathrm{vs} .>15 \mathrm{~mm})$, site of cerebral metastases (supratentorial alone $v s$. infratentorial \pm supratentorial), extracranial metastases (no $v s$. yes) and time from cancer diagnosis to SRS/FSRT ( $\leq 12 v s .>12$ months). The distribution of these factors is shown in Table I.

For the statistical analysis of the nine factors with respect to freedom from new brain metastases, the Kaplan-Meier method and the log-rank test were applied (8). $p$-Values of less than 0.05 were regarded as significant, and $p<0.10$ were interpreted as showing a trend for association. The factors that were significantly associated with freedom from new brain metastases and those factors showing a trend were used to develop the scoring tool.

\section{Results}

A KPS of 90-100 was associated with significantly better freedom from new brain metastases when compared to a KPS of 70-80 ( $p=0.013)$. In addition, a maximum total diameter of all cerebral lesions of $\leq 15 \mathrm{~mm}$ showed a trend for association with better freedom when compared to those with $>15 \mathrm{~mm}(p=0.09)$. Therefore, these two factors were incorporated into the scoring tool. The rates of freedom from new brain metastases at 6 and 12 months for all nine investigated factors are summarized in Table II.

When considering KPS and maximum total diameter of all cerebral lesions, the following scores were assigned: KPS $70-80=1$ point, KPS $90-100=2$ points, maximum total diameter $\leq 15 \mathrm{~mm}=2$ points and maximum total diameter $>15$ $\mathrm{mm}=1$ point. Thus, the total scores for individual patients were 2, 3 or 4 points. The corresponding rates of freedom from new lesions were $29 \%, 45 \%$ and $100 \%$, respectively, at 6 months following SRS/FSRT, and $0 \%, 45 \%$ and 100\%, respectively at 12 months $(p=0.027$, Figure 1$)$.

\section{Discussion}

A number of studies have been performed in recent years in order to improve the prognoses of patients with colorectal cancer with both primary and metastatic disease (9-19). The number of patients with colorectal cancer presenting with brain metastases is quite small but will likely increase in the future due to improvement in survival of such patients (1). Currently, more than half of all patients with brain metastasis from colorectal cancer have only a very limited number of cerebral lesions (2). In the case of those with 1-3 lesions, it is not clear whether local therapy such as SRS and FSRT alone would be the best treatment, or whether local therapy would be better combined with WBI. There are arguments for and against both treatment approaches. In two randomized
Table I. Distributions of investigated potential prognostic factors.

\begin{tabular}{lc}
\hline Factor & Number of patients $(\%)$ \\
\hline Age at the time of SRS/FSRT & \\
$\leq 65$ Years & $10(48)$ \\
$\geq 66$ Years & $11(52)$ \\
Gender & \\
Female & $6(29)$ \\
Male & $15(71)$ \\
Karnofsky Performance Score & \\
$70-80$ & $10(48)$ \\
$90-100$ & $11(52)$ \\
Primary tumor type & \\
Colon cancer & $14(67)$ \\
Rectal cancer & $7(33)$ \\
Number of brain metastases & \\
1 & $13(62)$ \\
$2-3$ & $8(38)$ \\
Maximum total diameter of all lesions & \\
$\leq 15$ mm & $9(43)$ \\
$>15$ mm & $12(57)$ \\
Site of cerebral metastases & \\
Supratentorial alone & $17(81)$ \\
Infratentorial \pm supratentorial & $4(19)$ \\
Extra-cranial metastases & $6(29)$ \\
No & $15(71)$ \\
Yes & $8(28)$ \\
Time from cancer diagnosis to SRS/FSRT & $13(62)$ \\
$\leq 12$ Months & \\
$>12$ Months & \\
\hline
\end{tabular}

SRS: Stereotactic radiosurgery; FSRT: fractionated stereotactic radiotherapy.

trials, the addition of WBI to SRS/FSRT led to greater decline in neurocognitive function than administration of a local therapy alone $(5,6)$. In the first of these trials, the rate of relevant neurocognitive deficits at 4 months following irradiation was $96 \%$ following SRS combined with WBI versus $24 \%$ following SRS alone $(p<0.001)(5)$. In the second randomized trial, decline in neurocognitive function at 3 months following irradiation was found in $92 \%$ and $64 \%$ of the patients, respectively $(p<0.001)(6)$. However, in both trials, the 12-month rates of intracerebral control, i.e. no progression of the treated lesions and freedom from new cerebral lesions, were significantly greater after the combined approach than after SRS alone $(5,6)$. In contrast, in a subgroup analysis of another randomized trial, the rates of preservation of neurocognitive function at 1 and 2 years following irradiation were greater after SRS plus WBI than after SRS alone, most likely due to improved intracerebral control (7). It is possible that some patients benefit from the addition of WBI to SRS/FSRT, whereas others do not.

When considering the ongoing discussion, it becomes obvious that it would indeed be helpful to identify those patients who may benefit from additional WBI prior to 


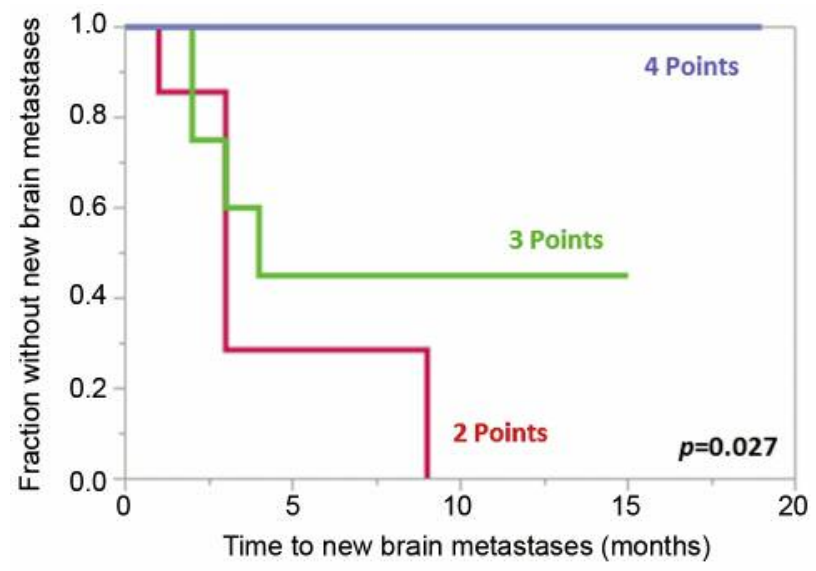

Figure 1. Kaplan-Meier curves of the three prognostic groups with 2 , 3 and 4 points. The p-value was determined with the log-rank test.

treatment. Therefore, this study was initiated to create a scoring tool that identifies those patients who receive SRS/FSRT alone but have a high risk of developing new brain metastases outside the irradiated areas. These patients may benefit by the addition of WBI to SRS/FSRT. In order to optimally evaluate the individual characteristics various tumors, separate tools should be available for the different primary tumor types causing brain metastases (20-22). Therefore, the present study focused on a single tumor entity, colorectal cancer. The prognostic tool created in this study was based on two factors, KPS and maximum total diameter of all brain metastases. Three groups of patients were identified with significantly different rates of freedom from new brain metastases. In the group with 2 points, the corresponding rates were $29 \%$ at 6 months and $0 \%$ at 12 months following SRS or FSRT alone. In other words, 71\% and $100 \%$ of the patients experienced new distant brain metastases after 6 and 12 months, respectively. Therefore, patients of this group likely would benefit from the addition of WBI in order to improve intracerebral control of metastatic disease. In contrast, $45 \%$ and $100 \%$ of the patients of the groups with 3 and 4 points, respectively, had not developed new distant brain metastases within 12 months following SRS or FSRT alone. Therefore, in patients with 4 points, WBI may be omitted in order to preserve neurocognitive function. In patients of the 3-point group, individual treatment decisions are required, particularly considering the patient preferences, regarding improved intracerebral control and less neurocognitive decline. The retrospective design of this study should be considered when interpreting these findings.

In conclusion, this study identified three groups with significantly different probabilities of new distant brain metastasis following SRS/FSRT alone. Patients of the group with 2 points could benefit from additional WBI, whereas
Table II. Freedom from new brain metastases.

\begin{tabular}{|c|c|c|c|}
\hline \multirow[b]{2}{*}{ Factor } & \multicolumn{2}{|c|}{$\begin{array}{l}\text { Freedom from new } \\
\text { brain metastases (\%) }\end{array}$} & \multirow[t]{2}{*}{$p$-Value } \\
\hline & $\begin{array}{c}\text { At } 6 \\
\text { months }\end{array}$ & $\begin{array}{l}\text { At } 12 \\
\text { months }\end{array}$ & \\
\hline \multicolumn{4}{|l|}{ Age at the time of SRS/FSRT } \\
\hline$\leq 65$ years & 57 & 38 & 0.99 \\
\hline$\geq 66$ years & 59 & 59 & \\
\hline \multicolumn{4}{|l|}{ Gender } \\
\hline Female & 60 & 30 & 0.46 \\
\hline Male & 56 & 56 & \\
\hline \multicolumn{4}{|l|}{ Karnofsky Performance Score } \\
\hline $70-80$ & 32 & 0 & 0.013 \\
\hline $90-100$ & 79 & 79 & \\
\hline \multicolumn{4}{|l|}{ Primary tumor type } \\
\hline Colon cancer & 60 & 48 & 0.88 \\
\hline Rectal cancer & 56 & 56 & \\
\hline \multicolumn{4}{|l|}{ Number of brain metastases } \\
\hline 1 & 66 & 55 & 0.63 \\
\hline $2-3$ & 42 & 42 & \\
\hline \multicolumn{4}{|l|}{$\begin{array}{l}\text { Maximum total diameter } \\
\text { of all lesions }\end{array}$} \\
\hline$\leq 15 \mathrm{~mm}$ & 75 & 75 & 0.09 \\
\hline$>15 \mathrm{~mm}$ & 41 & 21 & \\
\hline \multicolumn{4}{|l|}{ Site of cerebral metastases } \\
\hline Supratentorial alone & 61 & 49 & 0.87 \\
\hline Infratentorial \pm supratentorial & 50 & 50 & \\
\hline \multicolumn{4}{|l|}{ Extra-cranial metastases } \\
\hline No & 67 & 67 & 0.29 \\
\hline Yes & 56 & 37 & \\
\hline \multicolumn{4}{|l|}{$\begin{array}{l}\text { Time from cancer diagnosis } \\
\text { to SRS/FSRT }\end{array}$} \\
\hline$\leq 12$ Months & 67 & 67 & 0.92 \\
\hline >12 Months & 53 & 37 & \\
\hline Entire cohort & 59 & 50 & \\
\hline
\end{tabular}

SRS: Stereotactic radiosurgery; FSRT: fractionated stereotactic radiotherapy. Significant $p$-values are shown in bold.

WBI could be omitted in that with 4 points. In the group with intermediate risk ( 3 points), highly individual treatment decisions are required.

\section{Conflicts of Interest}

On behalf of all Authors, the corresponding Author states that there is no conflict of interest related to this study.

\section{References}

1 Tsao MN, Rades D, Wirth A, Lo SS, Danielson BL, Gaspar LE, Sperduto PW, Vogelbaum MA, Radawski JD, Wang JZ, Gillin MT, Mohideen N, Hahn CA and Chang EL: Radiotherapeutic and surgical management for newly diagnosed brain metastasis(es): An American Society for Radiation Oncology evidence-based guideline. Pract Radiat Oncol 2: 210-225, 2012. 
2 Siegel RL, Miller KD and Jemal A: Cancer statistics, 2017. CA Cancer J Clin 67: 7-30, 2017.

3 Rades D, Hornung D, Veninga T, Schild SE and Gliemroth J: Single brain metastasis: radiosurgery alone compared with radiosurgery plus up-front whole-brain radiotherapy. Cancer 118 : 2980-2985, 2012.

4 Rades D, Veninga T, Hornung D, Wittkugel O, Schild SE and Gliemroth J: Single brain metastasis: Whole-brain irradiation plus either radiosurgery or neurosurgical resection. Cancer 118 : 1138-1144, 2012.

5 Chang EL, Wefel JS, Hess KR, Allen PK, Lang FF, Kornguth DG, Arbuckle RB, Swint JM, Shiu AS, Maor MH and Meyers CA: Neurocognition in patients with brain metastases treated with radiosurgery or radiosurgery plus whole-brain irradiation: A randomised controlled trial. Lancet Oncol 10: 1037-1044, 2009.

6 Brown PD, Jaeckle K, Ballman KV, Farace E, Cerhan JH, Anderson SK, Carrero XW, Barker FG 2nd, Deming R, Burri SH, Ménard C, Chung C, Stieber VW, Pollock BE, Galanis E, Buckner JC and Asher AL: Effect of radiosurgery alone vs. radiosurgery with whole-brain radiation therapy on cognitive function in patients with 1 to 3 brain metastases: A randomized clinical trial. JAMA 316: 401-409, 2016.

7 Aoyama H, Tago M, Kato N, Toyoda T, Kenjyo M, Hirota S, Shioura H, Inomata T, Kunieda E, Hayakawa K, Nakagawa K, Kobashi $\mathrm{G}$ and Shirato H: Neurocognitive function of patients with brain metastasis who received either whole-brain radiotherapy plus stereotactic radiosurgery or radiosurgery alone. Int J Radiat Oncol Biol Phys 68: 1388-1395, 2007.

8 Kaplan EL and Meier P: Non-parametric estimation from incomplete observations. J Am Stat Assoc 53: 457-481, 1958.

9 Liang YH, Shao YY, Chen HM, Cheng AL, Lai MS and Yeh $\mathrm{KH}$ : Irinotecan and oxaliplatin might provide equal benefit as adjuvant chemotherapy for patients with resectable synchronous colon cancer and liver-confined metastases: A nationwide database study. Anticancer Res 37: 7095-7104, 2017.

10 Gkekas I, Novotny J, Pecen L, Strigård K, Palmqvist R and Gunnarsson U: Microsatellite instability as a prognostic factor in stage II colon cancer patients, a meta-analysis of published literature. Anticancer Res 37: 6563-6574, 2017.

11 Mercier J and Voutsadakis IA: A systematic review and metaanalysis of retrospective series of regorafenib for treatment of metastatic colorectal cancer. Anticancer Res 37: 5925-5934, 2017.

12 Kajitani T, Makiyama A, Arita S, Shimokawa H, Oda H, Shirakawa T, Baba E and Esaki T: Anti-epidermal growth factor receptor antibody readministration in chemorefractory metastatic colorectal cancer. Anticancer Res 37: 6459-6468, 2017.

13 Cirimbei C, Rotaru V, Chitoran E, Pavaleanu O and Cirimbei SE: Immediate and long-term results of radiofrequency ablation for colorectal liver metastases. Anticancer Res 37: 6489-6494, 2017.
14 Cicero G, Lo Re G, DE Luca R, Vernuccio F, Picone D, Midiri $\mathrm{M}$ and Lagalla R: Role of densitometric criteria in evaluation of effectiveness of antiangiogenic therapies in metastatic colorectal cancer: An Italian clinical experience. Anticancer Res 37: 51875192, 2017.

15 Nonaka T, Fukuda A, Maekawa K, Nagayoshi S, Tokunaga T, Takatsuki M, Kitajima T, Taniguchi K and Fujioka H: Clinical and oncological outcomes of laparoscopic lateral pelvic lymph node dissection in advanced lower rectal cancer: Singleinstitution experience. Anticancer Res 37: 5095-5100, 2017.

16 Margetis N, Kouloukoussa M, Pavlou K, Vrakas S and MariolisSapsakos T: Review: K-RAS mutations as the earliest driving force in a subset of colorectal carcinomas. In Vivo 31: 527-542, 2017.

17 Tanaka T, Kobunai T, Yamamoto Y, Murono K, Otani K, Yasuda K, Nishikawa T, Kiyomatsu T, Kawai K, Hata K, Nozawa H, Ishihara $\mathrm{S}$, and Watanabe $\mathrm{T}$ : Increased copy-number variation of mtDNA in an array-based digital PCR assay predicts ulcerative colitis-associated colorectal cancer. In Vivo 31: 713-718, 2017.

18 Yoshimoto T, Morine Y, Imura S, Ikemoto T, Iwahashi S, Saito Y, Yamada S, Ishikawa D, Teraoku H, Yoshikawa M, Higashijima J, Takasu C, and Shimada M: Maximum diameter and number of tumors as a new prognostic indicator of colorectal liver metastases. In Vivo 31: 419-423, 2017.

19 Nagata T, Nakase Y, Nakamura K, Sougawa A, Mochiduki S, Kitai $\mathrm{S}$ and Inaba $\mathrm{S}$ : Prognostic impact of a nutritional index including muscle volume in stage 4 colorectal cancer. In Vivo 30: 885-891, 2016.

20 Rades D, Huttenlocher S, Khoa MT, Thai PV, Hornung D and Schild SE: Number of cerebral lesions predicts freedom from new brain metastases after radiosurgery alone in lung cancer patients. Oncol Lett 10: 1109-1112, 2015.

21 Dziggel L, Dahlke M, Janssen S, Hornung D, Blanck O, Khoa MT, Schild SE and Rades D: Predicting the risk of new cerebral lesions after stereotactic radiosurgery (SRS) for brain metastases from breast cancer. Anticancer Res 35: 6793-6797, 2015.

22 Huttenlocher S, Sehmisch L, Schild SE, Blank O, Hornung D and Rades D: Identifying melanoma patients with 1-3 brain metastases who may benefit from whole-brain irradiation in addition to radiosurgery. Anticancer Res 34: 5589-5592, 2014.

Received March 26, 2018

Revised April 16, 2018

Accepted April 17, 2018 